\title{
Correlation of Personnel Management, Sustainable Development of Coal Mining Region and its Financial Security
}

\author{
Valeri Kopein ${ }^{1, *}$, Tamara Frolova ${ }^{1}$, and Elena Filimonova ${ }^{1}$ \\ ${ }^{1}$ Kemerovo State University, Institute of Economics and Management, Krasnaya St., 6, Kemerovo, \\ Russia
}

\begin{abstract}
The article examines the problems of sustainable social and economic development of the region of the mineral and raw material cluster associated with the search for the effectiveness of personnel management at the enterprise level. It is stated that under the conditions of economic turbulence, stagnation of production, sluggish growth of real income and wages, the issue of motivation and its connection with labor productivity becomes a major goal. A field study of personnel motivation was carried out and the results of an assessment of the management concept were obtained. It has been found that the main form of the motivational complex is the motivation model in which the external positive incentive of the personnel prevails over the external negative incentive which is greater than the internal motivation of the personnel. The conclusion is made that the motivation to labour exceeds the compulsion which is higher than the personal inclination to labour. In this case, the personal desire to effective work is low and subsequently it reduces labor productivity and increases staff turnover. The statement is justified that a decrease in the importance of external negative motives and (or) an increase in the importance of external positive incentives and internal incentives will lead to better motivation to work, which will contribute to an increase in labor productivity. In its turn, an enterprise with such attitude will be more resistant to external influences. It is concluded that this will stimulate the financial stability of the region in general and have a positive effect on financial security.
\end{abstract}

\section{Introduction}

Under conditions of the economic turbulence more and more attention in scientific research is paid to optimizing the costs of economic elements, industries, individual economic entities. The problem of achieving sustainable development is becoming more comprehensive and it covers all aspects of economic activity $[1,2]$. In the existing system of knowledge about the parameters of the sustainability of economic development there is a number of scientific works, reports of research results of both domestic and international scientists $[3,4]$. A special place is given to the issues related to the problems of financial

\footnotetext{
*Corresponding author: valkem2@mail.ru
} 
stability of the country, industries, regions, enterprises and organizations. This situation is justified by the general theoretical approach which defines finance as a key element in the economic activity of any economic element in a market economy. This determines the importance of the theory and practice of financial stability as well as security which affects other types and levels of security such as investment, food, energy security etc. $[5,6,7]$.

The aggravation of the situation in matters of sustainability of social and economic development and security was caused by the global economic crisis and a pandemic. Therefore at present the field of research on problems of stability and safety is constantly expanding while the number of "blank spots" that require more attention and study is also increasing. In the scientific circles the discussion about the directions of social and economic development and an increase of its sustainability is on the rise. An additional factor is the expansion of sanctions pressure on Russia, the assessments of which today are quite diverse $[8,9]$.

The object of the study is the region of the mineral resource cluster - the Kemerovo region or Kuzbass. The subject of the research is the motivation of labor activity at an enterprise as a factor in accelerating social and economic development and increasing the stability and financial security of the region. The key problems of the coal-mining region such as Kemerovo region (Kuzbass) are largely associated with the industrial specialization of the region, historically oriented towards the export of energy resources and the nondiversified structure of the economy. The crisis and falling demand have led to a reduction in production, shrinkage of small and medium-sized businesses and a decline in the standard of living of the population. Enterprises that are often on the edge of bankruptcy are looking for ways to stay afloat.

At the same time material, financial approaches as well as those that are not directly related to the increase in wages are considered. Among the latter, there is a concept of work motivation on which this article is focused.

\section{Methods}

The key and only approach to the study of the resources problems for the development of an enterprise, its stability and an impact on the overall level of security of the region and the country is the dialectical approach. This approach is generally recognized in the scientific community and expresses the content of modern epistemology.

Statistical reports and the results of Russian and international scientific research and experts' opinions were used as a data base for the application of the empirical methods. At the empirical level methods of economic monitoring, polling, interviewing and statistical processing were used. To assess the model of the motivational concept of personnel at a particular enterprise a technique was used that takes into account the advantages and disadvantages of many approaches to analyze the motivation of labor activity in an organization. As a basis we took and further refined the methodology of C. Zamfir "Working motivation structure", which allows not only to determine the degree of internal and external motivation, but also to diagnose external motivation both positive and negative [10].

In this approach as in other methods of studying the motivational mechanism, there are weaknesses which are primarily related to the peculiarity of verbal behavior and the fact that interpretation of the results needs to take into account the limit of the data. We believe that conducting such an assessment of the organization's existing personnel motivation model is a more informative feedback than a dialogue with an employee since it is more difficult to obtain direct real information about satisfaction with motivation. This allows us to determine the discrepancies in the views of managers and the factual situation on this issue [11]. On the basis of sociological studies conducted by various scientists in the field 
of labor motivational factors, a motivational model used in practice rather correctly reflects the realities of our time. In this model an individual's assessment of the importance of motivation factors at the same level of remuneration is correlated as follows. A person's inclination to labour has a greater motivational significance than an incentive to work, and this, in its turn, is of greater importance than compulsion to work.

Thus the following is considered to be the most favorable model for motivating personnel in an organization:

$$
I M>E P M>E N M,
$$

Where IM is an index of internal motivation of the personnel in an organization;

EPM is an index of the external positive motivation of the personnel in an organization;

ENM is the index of the external negative motivation of the personnel in an organization.

If in this model the signs of inequality are directed in the opposite direction this model of personnel motivation in the organization is the most unfavorable:

$$
I M<E P M<E N M \text {, }
$$

In this case it turns out that the significance of the employee's inclination to work is less than motivation, which is less than the significance of compulsion. With such a model of personnel motivation in an organization, we can expect the violations of labor discipline, an increase in staff turnover and, in general, general dissatisfaction with work.

A complex combination of elements of internal and external motivation and their importance/priority in relation to each other form a model of personnel motivation in an organization. The motivation model (motivational complex) used in the organization affects the quality of labor and its productivity, that is, the effectiveness of personnel management (see Table 1).

Table 1. Impact of the motivation model on staff efficiency.

\begin{tabular}{|c|c|c|}
\hline $\begin{array}{c}\text { Rank of } \\
\text { motivation } \\
\text { model }\end{array}$ & $\begin{array}{c}\text { Motivation model } \\
\text { (motivation complex) }\end{array}$ & $\begin{array}{c}\text { Quality and } \\
\text { efficiency of } \\
\text { work }\end{array}$ \\
\hline 1 & $\mathrm{IM}>\mathrm{EPM}>\mathrm{ENM}$ & high \\
\hline $2-3$ & $\mathrm{EPM}>\mathrm{IM}>\mathrm{ENM}$ & high \\
\hline $2-3$ & $\mathrm{EPM}>\mathrm{ENM}>\mathrm{IM}$ & average \\
\hline 4 & $\mathrm{IM}>\mathrm{ENM}>\mathrm{EPM}$ & average \\
\hline $5-6$ & $\mathrm{ENM}>\mathrm{IM}>\mathrm{EPM}$ & low \\
\hline $5-6$ & $\mathrm{IM}<\mathrm{EPM}<\mathrm{ENM}$ & low \\
\hline
\end{tabular}

To determine the rank of the motivational complex and its impact on the effectiveness of the workforce planning, an anonymous survey of employees is carried out and on the basis of the obtained group assessment of internal and external incentives conclusions about the model of personnel motivation can be made.

Thus the higher the value of the external negative motives, the less desirable is the motivation model due to the very concept of "negative motivation". To develop empirical data on external and internal incentives, a questionnaire was composed to conduct 
interviews ("Dear respondent, please answer the following questions, assessing them on a 5-point scale (5 - the maximum affirmative, 1 - the minimum affirmative)" - see Table 2).

Table 2. A questionnaire for building a social matrix and identifying a personnel motivation model in an organization

\begin{tabular}{|c|c|c|}
\hline No & Question & Point scale \\
\hline \multicolumn{3}{|c|}{ Internal incentives } \\
\hline 1 & Satisfaction from the work done & $\mathrm{x}$ \\
\hline 2 & Labour utility for society & $\mathrm{x}$ \\
\hline 3 & $\begin{array}{l}\text { Correspondence of the work to } \\
\text { vocation }\end{array}$ & $\mathrm{x}$ \\
\hline 4 & Interest in the labour results & $\mathrm{x}$ \\
\hline 5 & Possibility of creativity in work & $\mathrm{x}$ \\
\hline \multicolumn{3}{|c|}{ External positive incentives } \\
\hline 1 & Payment compensation level & $\mathrm{x}$ \\
\hline 2 & Working conditions & $\mathrm{x}$ \\
\hline 3 & Satisfaction with bonus system & $\mathrm{x}$ \\
\hline 4 & Social security & $\mathrm{x}$ \\
\hline 5 & Career promotion possibility & $\mathrm{x}$ \\
\hline \multicolumn{3}{|c|}{ External negative incentives } \\
\hline 1 & Fear of losing job & $\mathrm{x}$ \\
\hline 2 & Fear of sanctions for rules violation & $\mathrm{x}$ \\
\hline 3 & $\begin{array}{l}\text { Fear of inability to cope with } \\
\text { responsibilities }\end{array}$ & $\mathrm{x}$ \\
\hline 4 & $\begin{array}{l}\text { Fear of being transferred to a lower } \\
\text { paid position }\end{array}$ & $\mathrm{x}$ \\
\hline 5 & $\begin{array}{c}\text { Fear of criticism from colleagues and } \\
\text { administration }\end{array}$ & $\mathrm{x}$ \\
\hline
\end{tabular}

\section{Results}

The methodology for diagnosing the existing model of personnel motivation in an organization was tested in course of analyzing the effectiveness of personnel management at a small enterprise that provides security services. The survey was carried out in the category of "security guards" related to the main personnel which comprises $81 \%$ of the total personnel number. This category reflects the specifics of the main activity sphere of a 
private security enterprise and makes it possible to evaluate the results of a study of motivation at an enterprise with a high level of certainty. On the basis of the group assessment the significance of each group of incentives was determined including internal, external positive incentive as well as external negative incentives in the personnel motivation model on an enterprise. To assess the existing personnel motivation model in an organization the following scale of the integral group assessment of motives $Q$ was used:

- if $\mathrm{Q}>0.8$ - then the parameter (incentive) gets a high estimate;

- if $0.8>\mathrm{Q}>0.5$, then the parameter (incentive) receives an average estimate;

- if $\mathrm{Q}<0.5$ - then the parameter (incentive) gets a low score.

After collecting the primary data and subsequent processing, data were obtained to determine the motivation of the main personnel.

The following values of the integral group assessment were obtained:

- group index of internal incentives - 0.59;

- group index of external positive incentives - 0.72 ;

- group index of external negative incentives - 0.65 .

Consequently, at present, the company has developed a personnel motivation model in which the external positive motivation of personnel prevails over external negative motivation which is greater than the internal motivation. Thus, the results allow us to conclude that the motivation to work is superior to the compulsion to work, which is higher than the personal predisposition to work. This is not a perfect model; nevertheless it is not the worst option either.

On the one hand such an assessment indirectly reflects a decrease in the efficiency of the workforce planning. On the other hand such a model occupies the third position in the rank of preference for motivation models. In the general system of assessing motivation, this situation is quite common since nowadays any enterprise adapts the concept of personnel management to today's difficult economic conditions and looks for ways to optimize costs and to make motivation more flexible.

The concept of personnel management is built to a greater extent on the positive motivation of personnel, that is, the company's management gives preference to incentives to effective work rather than compulsion. But the personal predisposition to effective work among the personnel in this organization is low which causes a decrease in labor productivity and an increase in staff turnover.

This situation requires changes and modernization of the management concept to improve the efficiency of the enterprise. The growth of labor productivity today is becoming a significant factor in increasing the financial stability of an enterprise. The results obtained are not exclusive and inherent only to security services. The sluggish dynamics of the staff salaries of the overwhelming number of enterprises in the region of the mineral and raw materials cluster with an increase in production costs and costs reduces the level of financial security of enterprises and the sustainability of development. Ultimately, this negatively affects the investment environment of the region as a whole.

\section{Conclusion}

In the context of increasing nonlinearity of macroeconomic processes the development of enterprises, especially in regions of raw and industrial profile, faces the problem of adapting the economic mechanism to the growing gap between the growth rates of production costs and income from the business activities. Personnel motivation has not been considered in isolation from the need to increase labor productivity and with the stagnation of wages and real incomes; economic actors are forced to revise the existing concepts of motivation. The analysis of the concepts of personnel management using modern methods showed that the concept of management is based on positive motivation of 
personnel that is the management prefers the incentive to effective work rather than compulsion.

Currently the tendency to adjust the management concept is to reduce the importance of external negative incentives and (or) increase the importance of external positive incentives and especially internal motives to be engaged in the work. If a company sticks to these trends the motivation to work will be more sustainable and will contribute to the growth of labor productivity. In turn, an enterprise with such policy will be more resistant to external influences. This will increase the stability of the financial results of the industry as a whole and will have a positive impact on the financial security of the region. Strengthening its financial security will lead to more predictable dynamics of social and economic indicators and an increase in the investment attractiveness of the region.

\section{References}

1. M. Lamdabaso, D. Forey, European Journal of Innovation Management, 17(4), 492507 (2014)

2. V. Kopein, E. Filimonova, I. Kudryashova, K. Demidenko, E3S Web Conf. 41, 04036 (2018)

3. I.V. Voskoboinikov, Review of Income and Wealth, 12, 17 (2019)

4. A. Kopein, K. Demidenko, O. Fattakhova, T. Frolova, V. Lovchikov, I. Shurchanova, E3S Web Confer. 105, 04026 (2019)

5. L. Wildnerova, H. Blochliger, OECD Economics Department Working Papers, 1592, 25 (2019)

6. IFM, World economic outlook: The great lockdown (International Monetary Fund, Washington, 2020)

7. V. Kopein, E. Filimonova, T. Sinitsyna, T. Lantseva, N. Morozenko, E3S Web Conf. 41, 04038 (2018)

8. D. Gros, F. Mustilli, The effects of sanctions and counter-sanctions on EU - Russian trade flows (CEPS, Brussels, 2016)

9. Sanctions: how and when the EU adopt restrictive measures. URL: http://www.consilium.europa.eu/en/policies/sanctions/

10. K. Zamfir, The Working Motivation Structure method. URL: https://gigabaza.ru/doc/140511.html

11. I. Trubachev, T. Frolova, Features of staff motivation in public institutions (CHI, Nizhnevartovsk, 2021) 